\title{
Failure of Quintech Tx pacemaker caused by loss of stimulus-T interval shortening during exercise
}

\author{
T FYFE, J F ROBINSON \\ From the Cardiac Pacemaker Unit, Southern General Hospital, Glasgow
}

SUMMARY A 74 year old man with a Quintech $T x$ pacemaker experienced a reduction in his exercise capacity because his heart rate failed to increase with effort. This was shown to be caused by the failure of the interval between the delivered stimulus and evoked $T$ wave to decrease during effort where previously it had done so. Although the stimulus-T interval did not change during exercise, it did decrease in response to isoprenaline infusion and in response to pacing the heart at increasing rates. Catecholamine concentrations increased during exercise and the patient had normal thyroid function.

Pacemakers which increase the heart rate during exercise have been shown to improve exercise tolerance, ${ }^{1}$ and sensing of the stimulus-T interval shortening that occurs during exercise is one method by which this can be achieved. ${ }^{2}$ A patient is described who experienced a reduction in his exercise capacity because his Quintech $T x$ pacemaker failed to increase his heart rate during exercise; this was apparently because the interval between the delivered stimulus and evoked $\mathrm{T}$ wave did not shorten.

\section{Case report}

The patient, who had had a mitral valve replacement in 1971 at the age of 60 , had a Quintech Tx pacemaker implanted in January 1983 at the National Heart Hospital because he had four syncopal attacks during exercise and had also experienced dizziness during exercise. He was in atrial fibrillation with a resting heart rate around $50-60$ beats $/ \mathrm{min}$ with asymptomatic ventricular pauses of 2-4 s. On exercise testing his ventricular rate did not exceed 80 beats $/ \mathrm{min}$ and his systolic blood pressure fell from $180-190 \mathrm{~mm} \mathrm{Hg}$ to around $120 \mathrm{~mm} \mathrm{Hg}$ by the latter half of the first stage of the Bruce protocol. At

Requests for reprints to Dr T Fyfe, Medical Unit, Southern General Hospital, Glasgow G51 4TF. implantation the pacemaker did not sense $T$ waves because of their low amplitude but one month afterwards, exercise testing showed that the pacemaker was working satisfactorily and achieving paced heart rate during effort of 125 beats/min associated with an interval of $0.44 \mathrm{~s}$ between the delivered stimulus and evoked $\mathrm{T}$ wave. Eight months later (September 1983) he had three blackouts when exercising and noticed giddiness during exercise and on rising from a chair.

Testing subsequently showed that he was having ventricular extrasystoles during exercise which were thought to be interfering with pacemaker function. The system was adjusted and his exercise tolerance improved from stage I to stage III of the Bruce protocol on treadmill testing. The pacemaker increased his heart rate to 140 beats/min during exercise. His exercise capacity again deteriorated and exercise testing in October 1985 showed that the stimulus-T interval recorded on the surface electrocardiogram

Table 1 Plasma noradrenaline and adrenaline concentrations before and after exercise to 1 min into the second stage of the Bruce protocol

\begin{tabular}{|c|c|c|c|}
\hline & Resting & $\begin{array}{l}\text { End of } \\
\text { exercise }\end{array}$ & $\begin{array}{l}5 \text { min after } \\
\text { exercise }\end{array}$ \\
\hline $\begin{array}{l}\text { Noradrenaline }(\mathrm{nmol} / \mathrm{l}) \\
\text { Adrenaline }(\mathrm{nmol} / \mathrm{l})\end{array}$ & $\begin{array}{l}1.46 \\
0.94\end{array}$ & $\begin{array}{l}3.00 \\
2 \cdot 29\end{array}$ & $\begin{array}{l}1 \cdot 72 \\
1 \cdot 18\end{array}$ \\
\hline
\end{tabular}


Table 2 Effect of intravenous isoprenaline infusion on pacemaker rate and the stimulus- $T$ interval recorded on the surface electrocardiogram

\begin{tabular}{|c|c|c|c|c|c|c|c|c|c|c|c|c|}
\hline \multirow{4}{*}{$\begin{array}{l}\text { Time (min) } \\
\text { Pacemaker rate } \\
\text { (per minute) } \\
\text { Stimulus-T interval (s) }\end{array}$} & & \multicolumn{11}{|c|}{ Infusion rate } \\
\hline & & \multicolumn{5}{|c|}{$1 \mu \mathrm{g} / \mathrm{min}$} & \multicolumn{6}{|c|}{$2 \mu g / \min$} \\
\hline & 0 & 1 & 2 & 3 & 4 & 5 & 6 & 7 & 8 & 9 & 10 & 11 \\
\hline & $\begin{array}{l}71 \\
0.48\end{array}$ & $\begin{array}{l}71 \\
0.48\end{array}$ & $\stackrel{71}{0.48}^{71}$ & $\begin{array}{l}75 \\
0.48\end{array}$ & $\begin{array}{l}75 \\
0.48\end{array}$ & $\begin{array}{l}75 \\
0.48\end{array}$ & $\begin{array}{l}75 \\
0.48\end{array}$ & $\begin{array}{l}75 \\
0.48\end{array}$ & $\begin{array}{l}100 \\
0.44\end{array}$ & $\begin{array}{c}130 \\
0.42\end{array}$ & $\begin{array}{c}130 \\
0.40\end{array}$ & $\begin{array}{c}130 \\
0.42\end{array}$ \\
\hline
\end{tabular}

Table 3 Effect of increasing rates of pacing on the stimulus- $T$ interval recorded on the surface electrocardiogram

\begin{tabular}{lcccccc}
\hline Rate of ventricular pacing/min & 80 & 90 & 100 & 120 & 130 \\
Stimulus-T interval (s) & 0.48 & 0.44 & 0.44 & 0.42 & 0.40 & \\
\hline
\end{tabular}

by means of a Marquette triple channel machine at a paper speed of $50 \mathrm{~mm} / \mathrm{s}$ remained static at $0.48 \mathrm{~s}$ during exercise up to $1 \mathrm{~min}$ into stage II of the Bruce protocol and during recovery. The rhythm throughout was ventricular pacing at 71 beats/min. Table 1 shows that plasma adrenaline and noradrenaline concentrations were normal at rest and that the increase in noradrenaline concentration during exercise was also normal. The increase in adrenaline concentration was somewhat higher than expected but was not unreasonable for the conditions of extra stress of the test.

Isoprenaline was then infused intravenously at a rate of $1 \mu \mathrm{g} / \mathrm{min}$ for $5 \mathrm{~min}$, followed by $2 \mu \mathrm{g} / \mathrm{min}$ for $3 \mathrm{~min}$. It was stopped when occasional non-paced beats appeared. Table 2 shows that the stimulus-T interval shortened in response to isoprenaline and that the pacemaker sensed this and increased its rate. The increase in pacing rate from 71 to 75 beats/min without apparent shortening of the stimulus-T interval is probably the result of slight shortening of the stimulus- $T$ interval that was sensed intracardiacally by the pacemaker but was not apparent on the surface electrocardiogram.

Because the pacemaker did not increase the patient's heart rate during exercise it was replaced with a Medtronic Activitrax pacemaker which increases its rate by sensing increasing skeletal muscle noise during exercise. This improved his exercise tolerance and enabled him to exercise to $1 \mathrm{~min}$ into stage III of the Bruce protocol. At the time of implantation we paced the ventricle via the existing Quintech lead at various rates. The surface stimulus- $T$ interval shortened with increasing rates of pacing as shown in table 3 .

There was non-specific anaemia (haemoglobin $11 \mathrm{~g} / \mathrm{dl})$ and the blood urea concentration was marginally raised $(7.9 \mathrm{mmol} / 1$, normal upper limit $7.5 \mathrm{mmol} / \mathrm{l}$ ). The following investigations were normal-plasma thyroxine and thyroid stimulating hormone; serum sodium, chloride, calcium, and phosphate concentrations; liver function tests; Synacthen test (tetracosactrin); and urinary metadrenalines. The only drug that he was taking regularly was Moduretic (amiloride hydrochloride and hydrochlorothiazide).

\section{Discussion}

This patient's Quintech $T x$ pacemaker lost its capacity to increase its rate with effort because the patient's stimulus- $T$ interval failed to shorten. We showed that the stimulus- $T$ interval did shorten in response to isoprenaline infusion and that the pacemaker was capable of sensing this and increasing the heart rate. The pacemaker, therefore, was capable of functioning normally.

Catecholamine release is known to be important in causing shortening of the stimulus- $T$ interval during exercise ${ }^{3}$ but the possibility that the failure of the stimulus- $T$ interval to shorten might be due to failure of catecholamine release has been excluded. Because the stimulus- $T$ interval did not decrease during exercise despite an adequate rise in catecholamine concentrations, the obvious conclusion is that the heart had become less sensitive to catecholamines. We have excluded the commonest cause of catecholamine resistance which is hypothyroidism. The reason that the stimulus- $T$ interval did not decrease during exercise remains a mystery.

According to the manufacturers (J H Gray, personal communication) there has been only one other case in over 2000 implants of this type of pacemaker in which there was no change in the QT interval during exercise. This abnormality is difficult to recognise before pacemaker implantation, however, because the QT interval still changes in response to changes in heart rate per se (as it did in our patient when pacing rates were increased) and therefore the problem can only be recognised when the heart rate 
Failure of Quintech Tx pacemaker caused by loss of stimulus-T interval shortening during exercise

can be held constant during exercise. In order that the failure is not misdiagnosed as a pacemaker sensing problem it is important that this abnormality should be looked for in all cases where a Tx pacemaker fails to increase its rate during exercise.

We thank Professor J Reid, Stobhill Hospital, Glasgow, for measuring noradrenaline and adrenaline concentrations.

\section{References}

1 Fananapazir L, Rademaker M, Bennett DH. Reliability of evoked response in determining the paced ventricular rate and performance of the QT or rate responsive (Tx) pacemaker. $P A C E$ 1985;8:701-14.

2 Rickards AF, Norman J. Relation between QT interval and heart rate. New design of physiologically adaptive cardiac pacemaker. Br Heart $\mathcal{F}$ 1981;45:156-61.

3 Fananapazir L, Bennett DH, Faragher EB. Contribution of heart rate to QT interval shortening during exercise. Eur Heart $\mathcal{F}$ 1983;4:256-71. 